SVU- International Journal of Veterinary Sciences, 3 (2): 106-114, 2020.

Print ISSN: 2535-1826

\title{
Histomorphogenesis of the Pharyngeal roof in Muscovy Ducks (Cairina moschata)
}

\section{Fatma A. Madkour ${ }^{1 *}$, Kamal E. H. Abdalla ${ }^{2}$, Salma Ahmed Mohamed ${ }^{1}$}

${ }^{1}$ Department of Anatomy and Embryology of Veterinary Medicine, South Valley University, Qena 83523, Egypt. ${ }^{2}$ Department of Anatomy and Histology, Faculty of Veterinary Medicine, Assiut University, 71526, Assiut, Egypt.

\section{Abstract}

This study aimed to investigate the morphological characteristics of the pharyngeal roof of the developmental stages of Muscovy ducks from 1 to 60 days old. The statistical analysis revealed that the ratio of the pharyngeal roof to the total length of the oropharynx decreased with advancement of the age, which was recorded $19.44 \%$ at one-day age and $15.19 \%$ at 60 days age, as well as the infundibular cleft was increased in length approximately by one and half at 15 days and three folds at 60 days when compared with that of one-day-old. SEM in one-day-old showed that, the fine pharyngeal papillae on each side of the infundibular slit, whereas, two types of the papillae at 15 days but numerous different size and shape caudally directed papillae at 60 days, some of them which were present at the pharyngoesophageal junction were in appearance of the nails of the carnivores. Numerous openings of the sphenopterygoid salivary glands were scattered between these papillae, which were observed in older ages (60 days old) by few numbers in the shallow groove at the caudal commissure of the infundibular slit. The edges of the infundibular cleft were smooth in all developmental stages except at 60 days old where few, fine and caudally directed papillae were recognized. Histologically, the sphenopterygoid salivary glands were compound tubulo-alveolar mucous secretory glands which was surrounded by lymphatic aggregation in older ages. In all examined ages, lymphatic accumulation could be observed in the infundibular cavity which was surrounding the intraepithelial mucous glands.

Keywords: Duck, Pharyngeal roof, SEM, Spheniopterygoid salivary glands

DOI: 10.21608/svu.2020.32880.1061 Received: July 16, 2020 Accepted: September 21, 2020 Published: September 23, 2020.

*Corresponding Author: Fatma A. Madkour E-mail: madkour.f@vet.svu.edu.eg

Citation: Madkour et al., 2020 Histomorphogenesis of the Pharyngeal roof in Muscovy Ducks

(Cairina moschata). SVU-IJVS 2020, 3(2): 106-114.

Copyright: (C) Madkour et al. This is an open access article distributed under the terms of the creative common attribution license, which permits unrestricted use, distribution and reproduction in any medium provided the original author and source are created.

Competing interest: The authors have declared that no competing interest exists. 


\section{INTRODUCTION}

The Muscovy duck with caruncles around the eyes and beak is the only species derived from wild ducks of central and South America (Stastny,1985). The second most important birds of economic importance after fowl are duck and goose (Nickel et al., 1977). The oral and pharyngeal cavities of birds form one common cavity which is often called the oropharynx (King and McLelland, 1984) due to absence of soft palate. The latter authors suggested embryologically that line between the choanal and the infundibular slits is the boundary between the oral and pharyngeal cavities. The transition from the oropharyngeal roof to the esophagus is much more abrupt and clearly demarcated (Crole and Soley, 2010). The infundibular cleft at the pharynx lead to the opening of the right and left eustachian tubes, these tubes are short, broad structure in birds and opening directly into the oropharynx for equalizing pressure changes (Orosz, 1997). In ostrich, the pharyngeal tonsil is observed at the caudolateral part of the pharyngeal roof for protection from invading infections (Tadjalli et al., 2008). The distribution and number of pharyngeal papillae are related to the eating behavior of the birds (Madkour, 2018). These papillae assist in moving food toward the esophagus (King and McLelland, 1984). The literature shows that the anatomical information on the oropharynx is available but there is paucity of information on the embryonic and postnatal development of it in ducks. Therefore, the present work was carried out to explain the gross, scanning and microscopic anatomy to the developmental stages of the pharyngeal roof from 1 to 60 days old in Muscovy ducks.

\section{MATERIALS AND METHODS}

Forty nine healthy Muscovy ducks (Cairina moschata) were obtained from local farms in Assiut Governorate, Egypt. They were divided into 5 groups $(1,7,15$, 30 , and 60 days old) were used at this work. After slaughtering and complete bleeding, the heads were cut off and good washed by water and submerged in 10\% formalin, and then the pharyngeal roof was dissected. Finally, the morphological features and biometrical parameters of the pharyngeal roof were recorded for each bird by using the magnification lens and Precision Digital Vernier Caliper, and photographed the samples by using Panasonic Digital Camera. For SEM, the pharyngeal roof of 3 birds of only (from each group) of 1-, 15and 60-days old groups were used, the sample processing for SEM was preformed according to Madkour et al. (2019). For light microscopy examination, cross and longitudinal sections from the pharyngeal roof were taken from 3 birds of each age. The samples were processed for paraffin embedding. Sections were cut at the $3-5 \mu \mathrm{m}$ thickness by Microtome (Leica RM2235) and were stained with H\&E stain then examined with a light microscope Leica LM. The staining techniques were reviewed by (Bancroft et al. 2013). The present work was done following the guidelines of the Institutional Ethical Committee.

\section{RESULTS}

The roof of the pharyngeal cavity was extended from the line of separation between the choanal and infundibular slits to the pharyngoesophageal junction. In all age groups, the mucous membrane of the caudal end of the pharyngeal roof had been protruded caudally and forming curved boundary (pharyngoesophageal junction) which showed a sharp line of demarcation between the pharynx and esophagus. The morphometrically, the length of the pharyngeal roof was measured $6.08 \pm 0.73$, $6.24 \pm 0.63, \quad 8.19 \pm 0.69, \quad 14.80 \pm 0.91$, and $15.15 \pm 1.95 \mathrm{~mm}$ at $1,7,15,30,60$ days old, 
respectively. In general, in all examined birds, the pharyngeal roof had formed $15.19-19.44 \%$ of the total length of the oropharynx. The infundibular slit was a median longitudinal slit located in the caudal part of the roof of the pharyngeal cavity behind the choanal slit (Fig. 1).

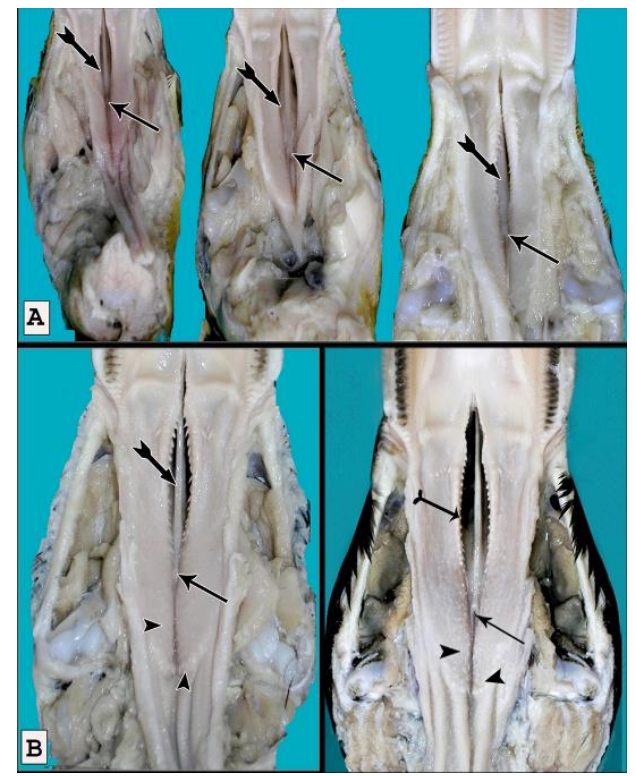

Fig. (1): Gross photographs of the roof of the caudal part of the oral and pharyngeal cavities at 1,7and 15 days (A) and of 30 and 60 days old ducks (B) from left to right, showing choanal slit (barbed arrow), infundibular slit (arrow), pharyngeal papillae (arrow heads).

It represented the common opening of both right and left auditory tubes within the roof of the pharynx. It was $2.84 \pm 0.11$, $4.104 \pm 0.16$, and $8.04 \pm 0.46 \mathrm{~mm}$ long in 1 , 15 , and 60 days old birds, respectively. Consequently, the infundibular cleft was increased in length with the advancement of the age as at 15 days old it constituted nearly one and half folds and at 60 days old three folds when compared with that at oneday-old. The caudal commissure of the infundibular cleft was terminated rostral to the level of the pharyngoesophageal junction by a variable distance in different age groups of the duck. This distance was
$2.35 \pm 0.17,3.59 \pm 0.14,5.02 \pm 0.61 \mathrm{~mm}$ at 1 , 15 , and 60 days old, respectively. Therefore, this distance at 15 days was increased about one and half folds and about two folds at 60 days old of one-dayold. The rostral and caudal commissures of the infundibular slit were narrow and had acute angles. The caudal commissure continued caudally with a shallow groove till the level of the pharyngoesophageal junction. This groove was smooth in all developmental studied stages. At 30-60 days old, a longitudinal row of minute openings was observed grossly on each side of this groove. The mucous membrane of the pharyngeal roof was smooth at one-day, 3-4 fine papillae were identified at the pharyngoesophageal junction at 7 days. These papillae increased in number and size and were directed caudally at 15 days. Moreover, at this age numerous, thin and caudally directed papillae were demonstrated on both sides of the infundibular slit. These papillae were concentrated more medially than laterally in relation to the infundibular slit. With the advancement of the age, at 30-60 days, these pharyngeal papillae became more distinct and regularly scattered in a nearly longitudinal manner (rows) on both sides of the infundibular cleft. They were mostly cone-shaped with pointed apices. Moreover, in these developmental stages, the most caudally situated pharyngeal papillae were arranged at the curved pharyngoesophageal junction. The papillae surrounding the infundibular cleft were continued rostrally with the papillae on the edges of the choanal slit. All statistical data of the pharyngeal roof were summarized in Table (1).

The results of SEM of the pharyngeal roof, at one-day-old bird showed that the fine papillae were scattered in the pharyngeal roof on each side of the infundibular slit. 
Table (1): The average dimensions (in $\mathrm{mm}$ ) of the pharyngeal roof.

\begin{tabular}{|c|c|c|c|c|c|}
\hline & 1 day & 7 days & 15 days & 30 days & 60 days \\
\hline \multicolumn{6}{|l|}{ Length of: } \\
\hline - Oropharynx & $31.44 \pm 0.68$ & $37.11 \pm 0.69$ & $49.48 \pm 1.07$ & & $98.11 \pm 6.33$ \\
\hline -Pharyngeal roof & $6.08 \pm 0.73$ & $6.24 \pm 0.63$ & $8.19 \pm 0.69$ & $14.80 \pm 0.91$ & $15.15 \pm 1.95$ \\
\hline Ratio(\%) of: & $19.44 \pm .02 \%$ & $17.02 \pm .01 \%$ & $16.49 \% \pm .01$ & $18.72 \%$ & $15.19 \pm .01 \%$ \\
\hline \multicolumn{6}{|l|}{ Infundibular slit: } \\
\hline -Total length & $2.84 \pm 0.11$ & $3.23 \pm 0.28$ & $4.10 \pm 0.16$ & $6.75 \pm 0.28$ & $8.04 \pm 0.46$ \\
\hline -Distance between it & $2.35 \pm 0.17$ & $2.16 \pm 0.26$ & $3.59 \pm 0.14$ & $4.50 \pm 0.08$ & $5.02 \pm 0.61$ \\
\hline \&pharyngoesophageal & & & & & \\
\hline junction & & & & & \\
\hline
\end{tabular}

At higher magnification, these papillae were directed caudally and had pointed apices (Fig. 2A, B). At 15 days, the pharyngeal papillae were increased in number and size. Moreover, two types of papillae could be identified; long conical papillae with pointed apices and short wedge-shaped papillae with blunt apices (Fig. 2C, D).

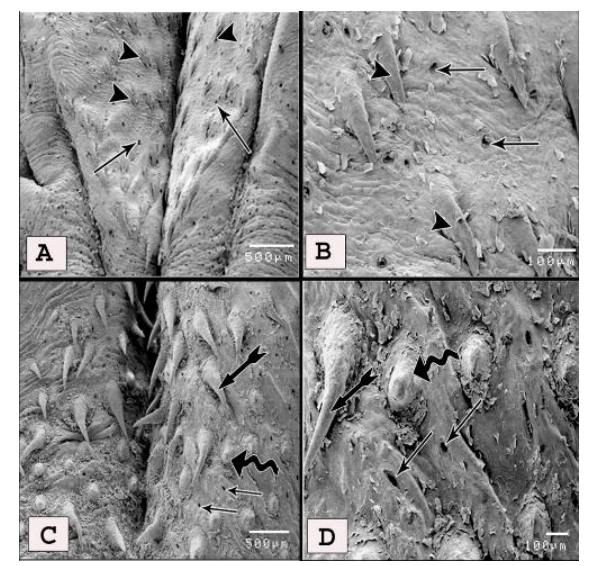

Fig. (2): (A, B) Scanning electron micrographs of the pharyngeal roof at one-day, $(\mathrm{C}, \mathrm{D})$ at 15 days old ducks showing fine papillae (arrow heads) and two types of pharyngeal papillae; long conical shaped papillae with pointed apices (barbed arrow) and short wedge shaped papillae (twisted arrow), openings of sphenopterygoid salivary glands (arrows).
With the advancement of the age, at 60 days, numerous and mainly caudally directed papillae of different size were demonstrated on the pharyngeal roof. These papillae were mostly conical in shape with wide base and pointed apex, with some of them were wedge-shaped (Fig.3A). The pharyngeal papillae at the pharyngoesophageal junction were longer than the others and some of them had the appearance of nails of the carnivores (Fig. 3B).

The infundibular slit in all groups under present investigation was represented by an elongated opening. The edges of the infundibular cleft were smooth in all developmental stages except at 60 days old where few fine and caudally directed papillae were recognized (Fig.3A). At oneday-old, very small-sized and caudally directed papillae were appeared on the edges of the shallow groove which represented the continuation of the caudal commissure of the infundibular slit. These papillae were increased in size with the advancement of the age (Fig.3A).

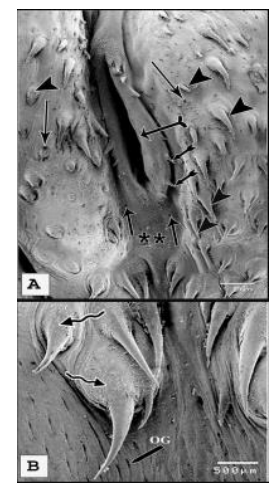

Fig. (3): (A, B) Scanning electron micrographs of the pharyngeal roof at 60 days old duck, showing infundibular slit (barbed arrow), shallow groove behind its caudal commissure (stars), fine few papillae on its edge (small barbed arrows), different shaped and sized pharyngeal papillae (arrow heads), openings of sphenopterygoid glands (arrows), openings of esophageal glands (OG), papillae like nails of the carnivores at the pharyngoesophageal junction (twisted arrows). 
The scanning electron microscopical findings indicated the presence of numerous openings of the sphenopterygoid salivary glands were scattered between the pharyngeal papillae on both sides of the infundibular slit (Figs. 2,3) in all age groups studied. Moreover, in older ages (60 days old) few openings of these glands were observed in the shallow groove lying behind the caudal commissure of the infundibular slit and were in addition to openings of the esophageal glands (Fig. 3A, B).

In cross paraffin sections at one-dayold, the lining mucosa of the pharynx was formed of lamina epithelialis and lamina propria. The lamina epithelialis consisted of non-cornified stratified squamous epithelium except at the level of the fine developing pharyngeal papillae, where they were cornified. At the edges of the infundibular slit, this epithelium was continued for a short distance and later transformed into pseudostratified columnar epithelium with cilia (respiratory epithelium) and interrupted by intraepithelial mucous glands (Fig. 4A, C). At this age, no sensory corpuscles were seen in the connective tissue of lamina propria of the pharynx. The connective tissue of lamina propria formed invaginations covered by epithelial folds which had compound tubulo-alveolar mucous secretory glands known as sphenopterygoid salivary glands (Fig. 4A, B). The glands were surrounded by connective tissue capsule. Connective tissue septa raised from the capsule and dividing the gland into glandular lobules. Each lobule consisted of secretory units which were lined by relatively low columnar epithelium cells with flattened basally located nuclei and foamy vacuolated cytoplasm. In this developmental stage the higher magnification of the pharyngeal papillae showed small size, with blunt apices (Fig.
4B). Few lymphatic infiltrations could also be observed just close to the margins of the infundibular edges surrounding the intraepithelial mucous glands (Figs. 4A, C).

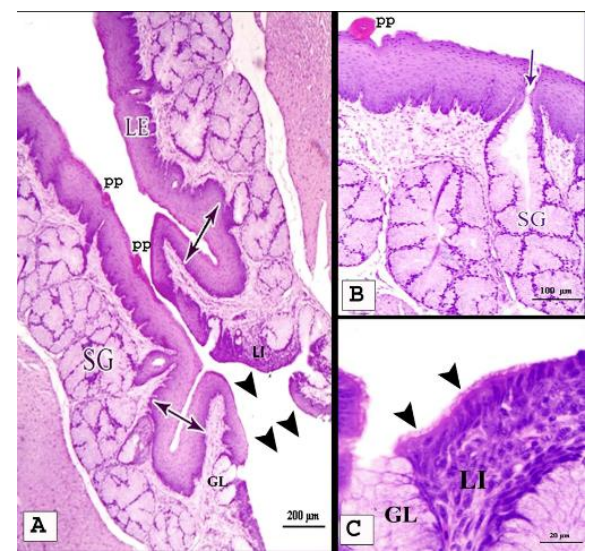

Fig. (4): (A-C) Photomicrographs of the cross section of the pharyngeal roof at one-day old duck, showing lamina epithelialis non-cornified (LE), fine developing pharyngeal papillae (PP), sphenopterygoid glands (SG) perforated epithelium (arrow), infundibular folds (double head arrows) and infundibular cavity (arrow heads) lining by respiratory epithelium with cilia (arrow heads) interrupted by intraepithelial mucous glands (GL) surrounded by few lymphatic infiltration (LI). H\&E stain.

At 7-15 days old, distinct papillary connective tissues lined by pharyngeal epithelium were seen. Moreover, the sphenopterygoid glands were well developed. The lining columnar epithelium showed foamy cytoplasm. The nuclei were very close to the basement membrane. At these ages, two types of cornified pharyngeal papillae, cone-shaped with pointed apices and short papillae with blunt apices were demonstrated (Fig.5A, B). The lymphatic infiltration was increased and could be observed at the level of the infundibular edges and surrounding intraepithelial mucous glands (Figs.5A, C).

At 30-60 days old, the pharyngeal roof was lined with thicker stratified squamous epithelium covered by a thin layer of keratin. More distinct papillary connective tissues covered by pharyngeal 
epithelium. The sphenopterygoid glands became well developed and more lobulated (Fig. 6A, B).

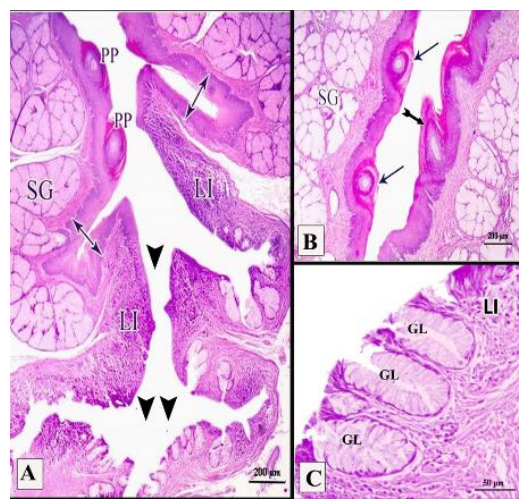

Fig. (5): (A, C) Photomicrographs of the cross section of the pharyngeal roof at 7 days, (B) at 15 days old ducks, showing 2 types of cornified pharyngeal papillae (PP); short blunt (arrows) and conical pointed apex papillae (barbed arrow), sphenopterygoid glands (SG), infundibular folds (double head arrows), infundibular cavity (arrow heads) lining by respiratory epithelium interrupted by intraepithelial mucous glands (GL) surrounded by lymphatic infiltration (LI) which also observed at the level of the infundibular edges. H\&E stain.

The pharyngeal papillae at these ages were highly cornified with different sizes (Fig. 6C). At these developmental stages, abundant lymphoid infiltration and lymphatic nodules were surrounded the intraepithelial mucous glands. The lymphatic nodules were large, numerous, and surrounded by connective tissue capsule. At the level of the pharyngoesophageal junction, the sphenopterygoid glands and their ducts were surrounded by lymphoid accumulation (Fig.6C, D).

\section{DISCUSSION}

Corresponding to all the previously mentioned statements by Hamilton (1952), Nickel et al. (1977) and McLelland (1975), the line of demarcation between the oral and pharyngeal cavities was located between the choanal and infundibular slits.

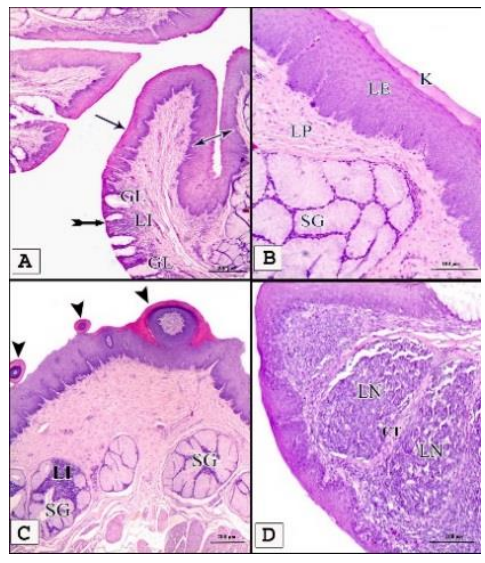

Fig. (6): (A, B) Photomicrographs of the cross section of the pharyngeal roof at 30 days, $(C, D)$ at 60 days old ducks, showing infundibular fold (double head arrow), transforming stratified squamous epithelium (arrow) into respiratory epithelium (barbed head) containing intraepithelial glands (GL) with lymphatic infiltration (LI), lamina epithelialis (LE) covered by thin layer of keratin (K), lamina propria (LP) contained sphenopterygoid gland (SG) which more lobulated with high columnar epithelium and surrounding by lymphatic infiltration (LI), different sized pharyngeal papillae (arrow heads), large lymphatic nodules (LN) surrounding by connective tissue capsule (CT). H\&E stain.

On the other hand, Hodges (1974) mentioned that the point of junction of the oral and pharyngeal cavities is situated near the glottis in the fowl. While, Hassouna (2002) claimed that the distance between the rostral end of the choanal cleft to the pharyngeo-esophageal junction can be considered as the pharyngeal cavity. The statistical data in present investigation revealed that the ratio of the length of the pharyngeal roof to that of the oropharyngeal roof was decreased with advancement of the age, which was $19.44 \%$ at one-day-old and became $15.219 \%$ at 60 days old. This ratio is recorded $12.27 \%$ in turkey (Sayed et al., 2016) and $13.64 \%, 27.18 \%$ in laughing dove and Japanese quail respectively (Madkour, 2018). 
The present work showed that the pharyngeal roof was smooth at one-day-old. With the advancement of the age, few fine pharyngeal papillae were appeared on each side of the infundibular slit which became more distinct and regularly scattered in a nearly longitudinal manner at 60 days. In this respect, the pharyngeal roof had fine small papillae in Japanese quail (Madkour, 2018) and turkey (Sayed et al., 2016). Hassouna (2002) elucidated in duck that, the pharyngeal papillae surrounding the choanal slit are long, formed an elevated root encircled with concentric layers of mucosal folds and become shorter on the sides of the infundibular slit, each two or three papillae originate by a single root. And the pharyngeal roof of budgerigar had several filiform papillae distributed along the midline (Evans, 1996). These papillae assist in the movement of the food towards the esophagus (King and McLelland, 1984). However, other studies showed that the pharyngeal roof is free from papillae in laughing dove (Madkour, 2018), falcon (Abumandour, 2014), and cattle egret (Moussa and Hassan, 2013). As viewed by SEM, the pharyngeal papillae were of two types; long conical and short wedge-shaped papillae at 15 days old and became numerous papillae of different size and mostly were conical in shape with wide base and pointed apex but some of them were wedge-shaped at 60 days old.

Our results revealed that the limit between pharynx and esophagus was represented by the pharyngoesophageal junction and had several papillae appearing like carnivore's nails. At this point, the pharyngeal roof is demarcated from the esophagus by transverse serrated mucosal fold in laughing dove and well-marked transverse row of large wedge-shaped papillae in Japanese quail (Madkour, 2018), duck (Hassouna, 2002) and guinea fowl (Jayachitra et al., 2015). In house sparrow, the pharyngeal roof is demarcated from the esophagus by 18-20 caudomedially directed small-sized pointed papillae (Abumandour,2018). Moreover, Mahdy (2020) reported in pigeon that the pharyngoesophageal junction represents by elevated transverse mucosal fold bear a transverse row conical-shaped papilla with pointed apices. In contrast, Tadjalli et al. (2008) reported that there is no transverse row of papillae at the junction with the esophagus in ostrich.

Morphometrical data showed that the infundibular slit was increased in length by nearly one and half folds at 15 days and three folds at 60 days age when compared with that of one-day-old bird and was recorded $2.84 \mathrm{~mm}$. The length of the infundibular slit in ostrich is $1.97 \mathrm{~cm}$ (Tadjalli et al., 2008), $2.53 \mathrm{~mm}$ in laughing dove and $3.83 \mathrm{~mm}$ in Japanese quail (Madkour, 2018). While it measures 6.93 $\mathrm{mm}$ in turkey (Sayed et al., 2016). Erdogan and Alan (2012) recorded that this length is $1.41 \mathrm{~mm}, 3.69 \mathrm{~mm}$ in the European magpie and Common raven, respectively. When viewed with SEM, the edges of the infundibular slit were smooth in all developmental stages as mentioned in laughing dove (Madkour, 2018) and pigeon (Mahdy, 2020) except few fine and caudally directed papillae were recognized at 60 days old. Hassouna (2002) in duck and Ali (2004) in ostrich reported that the surface epithelial cells at the infundibular slit appears covered with microvilli of variable length and density.

Under light microscope, the pharynx was lined by non-cornified stratified squamous epithelium except at the level of pharyngeal papillae which mostly subject to abrasion. Hodges (1974) mentioned that the pharynx in fowl is lined by a many-layered stratified squamous epithelium, lacking in a surface cornified layer. Our results reported 
that the lymphatic infiltration surrounding the intraepithelial mucous glands at the margins of the infundibular slit had increased with the advancement of the age and changed to large, numerous lymphatic nodules surrounded by connective tissue capsule. These nodules termed pharyngeal tonsil (King and McLelland, 1984) and tubal tonsils (Nickel et al., 1977). The latter authors added that these tonsils are abundant in geese than in pigeon. The present study was in agreement with the observations recorded by previous authors (Hodges, 1974; Ohshima and Hiramatsu, 2000; Hassouna, 2002) that the lymphoid accumulation was located in connective tissue septa of the salivary glands and around their ducts, which has an important role in immunity against infections by viruses, bacteria and any foreign bodies (Tadjalli et al.,2008).

\section{CONFLICT OF INTEREST}

The authors declare that there is no conflict of interest.

\section{REFERENCES}

Abumandour, M. M. (2014): Gross anatomical studies of the oropharyngeal cavity in Eurasian hobby (Falconinae: Falco Subbuteo, Linnaeus 1758). Journal of Life Sciences Research 1(4): 80-92.

Abumandour, M. M. (2018): Surface ultrastructural (SEM) characteristics of oropharyngeal cavity of house sparrow (Passer domesticus). Anatomical Science International 93(3): 384-393.

Ali, S. A. M. (2004): Some morphological studies on the oropharynx of the ostrich (Struthio camelus).Thesis,
M.V.Sc., Menoufyia University, Egypt.

Bancroft, J. D., Layton, C. and Suvarna, S. K. (2013): Bancroft's Theory and Practice of Histological Techniques.7th edition. Churchill Livingstone.

Crole, M. R. and Soley, J. T. (2010): Gross morphology of the intra-oral rhamphotheca, oropharynx and proximal esophagus of the emu (Dromaius novaehollandiae). Anatomia Histologia Embryologia 39: 207-218.

Erdogan, S. and Alan, A. (2012): Gross Anatomical and Scanning Electron Microscopic Studies of the Oropharyngeal Cavity in the European Magpie (Pica pica) and the Common Raven (Corvus corax). Microscopy Research and Technique 75: 379-387.

Evans, H. E. (1996): Anatomy of the budgerigar and other birds. In Diseases of Cage and Aviary Birds (RossKopf, W. J., and R.W. Woerpel, edn.). 3rd Ed. A Lea \& Febiger, Williams \&Wilkins A. Waverly Company, Philadelphia, USA.

Hamilton, H. L. (1952): In Lillie's Development of the chick,.3rd Ed. Henry Holt and Comp. INC. New York.

Hassouna, E. M. E. (2002): Morphological studies on the pharyngeal cavity of duck (Anas bousius domesticus). Assiut Vet. Med. J. 47: 21-41.

Hodges, R. D. (1974): The histology of the fowl, Academic Press. London, New York and San Francisco.

Jayachitra, S., Balasundaram, K., Iniyah, K. S., S. and Tamilselvan, S. (2015): 
Morphology of oropharyngeal cavity in guinea fowl (Numida meleagris). International Journal of Advanced Multidisciplinary Research IJAMR 2: 99-102.

King, A. S. and McLelland, J. (1984): Birds, their structure and function. 2nd Ed., Bailliere Tindall, 1 St. Annes Road.

Madkour, F. A. (2018): Characteristic features of the pharyngeal cavity of the laughing dove (Streptopelia senegalensis aegyptiaca) and japanese quail (Coturnix coturnix). Assiut Vet. Med. J. 64 (159) 52-59.

Madkour, F. A., Abdalla, K. and Mohamed, S. (2019): Choana Morphogenesis in the Post Hatching Developmental Stages of Muscovy Ducks. SVUInternational Journal of Veterinary Sciences 2 (2): 13-26.

Mahdy, M. A. (2020): Comparative gross and scanning electron microscopical study of the oropharyngeal roof of young and adult domestic pigeons (Columba livia domestica). Microscopy Research and Technique.

McLelland, J. (1975): Aves digestive system. In: Getty, R. (Ed.). Sisson and Grossman's The Anatomy of the Domestic Animals.5th Ed. Vol. 2. W. B. Saunders Co., Philadelphia and London.1857-1865.

McLelland, J. (1979): Digestive system. In: Form and Function in Birds.(King, A., McLelland, J., Ed.)Academic Press, London.69-181

Moussa, E. A. and Hassan, S. A. (2013): Comparative gross and surface morphology of the oropharynx of the hooded crow (Corvus cornix) and the cattle egret (Bubulcus ibis). Journal of Veterinary Anatomy 6(1): 1-15.

Nickel, R., Schummer, A. and Seiferle, E. (1977): Anatomy of the domestic birds. 2nd Ed. Vol. 5. Verlag paul parey. Berlin and Hamburg.

Ohshima, K. and Hiramatsu, K. (2000): Distribution of $\mathrm{T}$-cell subsests and immunoglobulin-containing cells in nasal-associated lymphoid tissue (NALT) of chickens. Histology Histopathology 15: 713-720.

Orosz, S. (1997): Anatomy of the Respiratory and Digestive Systems: In Avian Medicine and Surgery edited by Altman, R. B.; Clubb, S. L.; Dorrestein, G. M. and Queensberry, K., W. B. Saunders Company, Philadelphia, London and Toronto.

Sayed, R. K. A., Abdelmohaimen, M. S., Ahmed, K. A. and Kamal, E. H. A. (2016): Gross Anatomical, Light and Scanning Electron Microscopic Studies on the Pharyngeal Roof of Turkey (Meleagris gallopavo): Comparative Study. Journal of Advanced Veterinary Research 6 (4). 112-117.

Stastny, K. (1985): Birds of Sea and Fresh Water.Hamlyn, London.

Tadjalli, M., Mansouri, S. H. and Poostpasand, A. (2008): Gross anatomy of the oropharynx cavity in the ostrich (Struthio camelus). Iranian Journal of Veterinary Research 9: 316-323. 